See discussions, stats, and author profiles for this publication at: https://www.researchgate.net/publication/324125593

\title{
Relations Between Parenting and Adolescent's Attachment in Families Differing in Solidarity Patterns
}

Article in Review of Social Development · March 2018

DOI: $10.1111 /$ sode. 12297

CITATION

1

4 authors:

Katarzyna Lubiewska

University of Warsaw

22 PUBLICATIONS 113 CITATIONS

SEE PROFILE

Gisela Trommsdorff

Universität Konstanz

375 PUBLICATIONS 4,221 CITATIONS

SEE PROFILE
READS

65

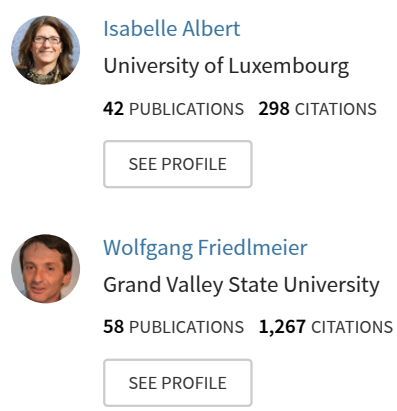

Some of the authors of this publication are also working on these related projects:

Combination of emic and etic approach to attachment and parenting (CEE-PaAtt) View project

Emotion socialization in cultural perspective View project 


\title{
Relations Between Parenting and Adolescent's Attachment in Families Differing in Solidarity Patterns
}

\author{
(1) \\ Katarzyna Lubiewska ${ }^{(\mathbb{D}}$ \\ Institute of Psychology, Kazimierz Wielki University, Bydgoszcz, Poland \\ Faculty of Psychology, University of Warsaw, Warsaw, Poland \\ Isabelle Albert \\ INSIDE - Integrative Research Unit on Social and Individual Development, University of \\ $\checkmark$ \\ Luxembourg, Luxembourg \\ Gisela Trommsdorff \\ Department of Psychology, University of Konstanz, Konstanz, Germany \\ Wolfgang Friedlmeier \\ Psychology Department, Grand Valley State University, Allendale, MI, USA \\ Corresponding author: \\ Katarzyna Lubiewska \\ Institute of Psychology, Kazimierz Wielki University, Poland \\ Address: ul. Staffa 1, 85-864 Bydgoszcz, Poland. \\ Phone number: +48 (052) 3708401; E-Mail: lubkat@ukw.edu.pl; \\ katarzyna.lubiewska@psych.uw.edu.pl
}

This article has been accepted for publication and undergone full peer review but has not been through the copyediting, typesetting, pagination and proofreading process which may lead to differences between this version and the Version of Record. Please cite this article as an 'Accepted Article', doi: 10.1111/sode.12297 


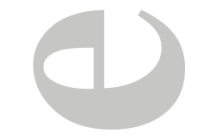

Abstract

To explain attachment development in adolescence in different contexts we applied the family solidarity model (e.g., Bengtson, 2001) generally used to analyze intergenerational adult children-elderly parents relations. The model differentiates four family solidarity patterns which were assumed in our study to occur in adolescent-parent relations, though with a different distribution. We tested a susceptibility hypothesis assuming that effects of parenting will be stronger in family patterns with higher, compared to lower, affectual solidarity. A sample of Polish adolescents, their mothers $(N=570$, both $)$, and their fathers $(N=290)$ was surveyed as part of the Value-of-Children-Study (Trommsdorff \& Nauck, 2005). Four family patterns were identified: highly affectual amicable and harmonious; and less affectual and most frequently displayed detached and disharmonious patterns. The parenting susceptibility hypothesis was supported: For amicable and harmonious families, adolescents' perception of maternal rejection was more strongly related with their attachment compared to the other family types. Partly in line with our hypothesis, effects of paternal rejection on adolescents' attachment were strongest in amicable families, however not significant in harmonious families. The study demonstrates that the relation between parenting on adolescents' attachment representation is influenced by the pattern of family parentschild relations.

Keywords: Family relations, attachment, parenting, intergenerational relations, adolescence. 


\section{Relations Between Parenting and Adolescent's Attachment in Families Differing in Solidarity}

\section{Patterns}

Sensitive parenting explains attachment security development in childhood (Ainsworth, Blehar, Waters \&Wall, 1978; de Wolff \& van IJzendoorn, 1997) but still little is known about parenting factors inhibiting or fostering the development of secure attachment in adolescence when children start to renegotiate their relationships toward parents in order to balance autonomy and relatedness needs. Attachment security in adolescence is best conceptualized as an organizational construct capturing multiple facets of behavior and cognition. It is tied to adolescents' capacities to maintain a sense of relatedness while negotiating autonomy with/from close others, and to developing emotion regulation capabilities to support this process (Allen \& Manning, 2007; Allen, Porter, McFarland, McElhaney, \& Marsh, 2007). It is assessed as an internal state of mind (i.e., mental representation) rather than a feature of a particular attachment relationship, and develops intensively in adolescence (Allen et al., 2003).

In this developmental period, sensitive parenting is defined through parental warmth, support, and attunement to adolescent child bids, and it is related with the parent-adolescent ability to amicably reaffirm their relationship while disagreeing (Allen et al., 2003). According to Interpersonal Parental Acceptance-Rejection Theory (IPARTheory), parenting warmth consists of (high) acceptance and (low) rejection dimensions, which are evidenced to parallel maternal sensitivity in attachment theory (Hughes, Blom, Rohner, \& Britner, 2005; Rohner, 2016). Rejection is based on observable parental hostility, unavailability, and/or child subjective perception of being unloved. According to IPARTheory, rejected children tend to become overly dependent or defensively independent from the caregiver, which corresponds with insecure, ambivalent or avoidant attachment patterns (Hughes et al., 2005; Rohner, 2016). Studies supporting this notion yielded that rejection of both parents was found to explain insecure attachment in early adulthood within the IPART framework (Casselman \& McKenzie, 2015; Lubiewska, Mayer, Albert, \& Trommsdorff, 2016) and beyond this approach (e.g., Hinnen, Sanderman, \& Sprangers, 2009). 
Moreover, unlike in infancy, research on adolescence suggests that not mainly sensitive caregiving of mothers but of both parents is crucial in attachment security development (Allen et al., 2007; Oudekerk, Allen, Hessel, \& Molloy, 2015). Even though adolescents seems to be in general more secure in relations with mothers than with fathers (Doyle, Lawford, \& Markiewicz, 2009), some studies indicate that parenting of fathers may explain emotional development in adolescence above and beyond mother-child relationship quality (Casselman \& McKenzie, 2015; Tighe, Birditt, \& Antonucci, 2016; Rohner, 2016).

Perceptions of parents as the primary source of support decline in adolescence and peers start to be considered as the main support providers (Carlivati \& Collins, 2007). Yet, a warm family climate was evidenced to add to adolescents' well-being (Anthony \& Stone, 2010) or attachmentrelated outcomes (Ackerman et al., 2013; Ratto, Doyle \& Markiewicz, 2016) above individual differences (Ackreman et al., 2013), peers, or school (Williams \& Anthony, 2015). Furthermore, even though susceptibility to peer pressure increases during identity formation in early adolescence, in families where emotional bonds are warm values and behaviors of parents are more salient and attractive to adolescents (Laursen \& Collins, 2009). Adolescents in these families handle autonomy and relatedness more successfully (Oudekerk et al., 2013) and are less susceptible to peer pressure (Williams \& Anthony, 2015). Turning from parents, in particular from the mother, to peers in fulfilling attachment needs was found especially salient for adolescents insecurely attached to their mothers (Markiewicz, Lawford, Doyle, \& Haggart, 2006).

We aim in the present study to test the assumption that the family solidarity model describing the family climate - can be useful in explaining differences in the strength of relation between adolescents' perception of parenting and their general (not relation-specific) mental representation of attachment. Previous studies assessed family climate using measures of family relations, e.g. using parent(s)-child affect and conflict variables (e.g., Belsky, Jaffee, Hsieh, \& Silva, 2001). In contrast to the variable-centered approach of testing effects of family climate on child-parent relations, we apply a person-centered approach as part of the family solidarity model 
(e.g., Bengtson, 2001). This allows analysis of family climate using multiple dimensions of family relations to distinguish family patterns. The person-centered approach allows looking at different aspects of the adolescent-parents-relationship simultaneously, therefore, allowing the discovery of synergetic effects which would not have been possible when studying effects of each dimensions of family relations separately (Bergman, 2001).

\section{Family Solidarity Patterns}

Solidarity is a key feature of the union between family members that characterizes family relations and creates the context of individual development (Albert, Ferring, \& Michels, 2013; Bengtson, 2001; Olson, 2000; Schwarz, Trommsdorff, Albert \& Mayer, 2005). The solidarity model was developed in the context of adult child-parent relations and up to date, this framework was used to investigate intergenerational relations in a family in later stages of the human life-span with few exceptions (e.g., Attar-Schwartz, 2015; Michels, Albert, \& Ferring, 2011).

Bengtson and Schrader (1982) outlined six distinct dimensions defining intergenerational solidarity: associational (physical integration/isolation), structural (geographic proximity/distance), affectual (e.g. intimacy), consensual (e.g., agreement/dissent in values and norms between family members), functional (dependency/autonomy), and normative (familism) dimensions. Reports from children or from children and parents are used across studies to assess solidarity dimensions using different assessment tools (e.g., Attar-Schwartz, 2015; Belsky, Jaffee, Caspi, \& Moffitt, 2003). Based on these dimensions and using various clustering methods (e.g., LCA, $k$-mean clustering, or dichotomization of data), different authors have found similar, yet not always identically labeled, clusters/patterns of families.

Four family solidarity patterns have emerged from various recent studies (Ferring, Michels, Boll, \& Filipp, 2009; Friedlmeier \& Lubiewska, 2012; Giarrusso, Silverstein, Gans, \& Bengtson, 2005; Katz, Lowenstein, Phillips, \& Daatland, 2005; Nauck, 2014; Steinbach, 2008). They differed mainly by the extent of intimacy and conflict. Amicable (also labeled as close) families are characterized by high intimacy and low conflict (from $22 \%$ to $68 \%$ of families across studies). 
Harmonious (also labeled as steady) families - although still described as close - are emotionally more distant than amicable families (from $40 \%$ to $47 \%$ of families). In ambivalent families, intimacy and conflict are supposed to be rather balanced and both usually high (from 5\% to 34\% of families). Detached, (also labeled as civil or distant) families are characterized by more distant emotional ties where low conflict and low affect are more likely (from $9 \%$ to $28 \%$ of families). Additionally, some studies (Ferring et al., 2009; Nauck, 2014) distinguished detached and disharmonious families, or only one between them. Disharmonious, compared to detached pattern, is characterized more by high conflicts accompanied by low intimacy (from $5 \%$ to $21 \%$ of families). Up to date, the family solidarity framework was found to be useful in understanding individual (Attar-Schwartz, 2015; Belsky et al., 2003; Belsky et al., 2001) and family-level (Fasang $\&$ Raab, 2014) dynamics. For example, parents-child affectual solidarity (a combination of intimacy and emotional support in relation with parents) was evidenced to moderate the extent of a relation between adolescents' closeness to grandparents and their adjustment (Attar-Schwartz, 2015), or the extent of intergenerational transmission in a family (Fasang \& Raab, 2014). Instead of using variable-centered methods (e.g., correlational designs), this study is one of the first to use a personcentered method in order to test the distribution of family solidarity patterns in adolescence.

\section{Distinction between Attachment and Affectual Solidarity}

Considering the six solidarity dimensions mentioned above, affectual solidarity is similar to the attachment construct. However, it is important to distinguish these two concepts, since we aim to study interrelated constructs of attachment and affectual solidarity. Mental representations of attachment with close others develop basing on past and current attachment relationships and define the extent of comfort in closeness with an attachment figure and anxiety about the relationship. Attachment is related with the activation of the need for closeness in times of stress (Mikulincer \& Shaver, 2007) and serves for protection that may be obtained by proximity seeking with an attachment figure. Different than attachment, the affectual solidarity describes intergenerational relations in every-day (not stress-evoked) situations and relates to the quality of communication, 
liking, the extent of the parent-child emotional disclosure, or the emotional support exchange among family members (Allen, Stein, Fonagy, Fultz, \& Target, 2005; Cortina \& Liotti, 2010; Furman \& Buhrmester, 2009). Affectual solidarity is characterized by intimacy and admiration exchanged between family members. Although attachment and affectual solidarity can be interrelated (Merz, Schuengel, \& Schulze, 2007), quality of attachment is evidenced to be the core characteristic of individuals predicting their social and emotional development, whereas quality of parent-child relation fosters or inhibits this process.

\section{The Present Study}

We aim in the present study to: answer one research question - What are the types and distribution of solidarity patterns in families of adolescent children?; and to test a hypothesis assuming that the solidarity patterns moderate the link between parenting and adolescent attachment. Several assumptions underlie our research question and hypothesis.

First, regarding the developmental period of adolescence and using person-centered approach, we expect the same family patterns as reported in studies with adult children but a different distribution for the following reasons. First, frequency of contacts (e.g., visits) is not an adequate proxy of solidarity in child-parent relations because adolescents still live with their parents. Second, the direction of adolescent-parent attachment relationships goes still from the weaker adolescent to a stronger parent who serves as the support provider (Merz et al., 2007). Unlike in adulthood, in adolescence, the opposite direction may indicate the occurrence of less adaptive processes related with a parent-child role-reversal (Macfie, Fitzpatrick, Rivas, \& Cox, 2008). Finally, the negotiation of autonomy and its relation to maintenance of relatedness with parents, as well as the parental response to these processes may result in different distributions of solidarity patterns and adolescents' perceptions of their own family relations. Adolescents may deidealize parents (Allen et al., 2003), experience more conflicts with them, and/or perceive these conflicts as more severe (Laursen \& Collins, 2009) than adult children. Therefore, we asked 
whether - in contrast to studies with adult children - disharmonious and detached patterns of family solidarity will be represented stronger than amicable and harmonious patterns in our study.

The main aim of our study was to test the extent to which patterns of family solidarity moderate parenting-attachment link. These results will add to the previous studies in which affectual solidarity dimension was used as a single moderator of individual- and family-level processes (e.g., Attar-Schwartz, 2015). We built our hypothesis on studies indicating that in families with a warm family climate, adolescents' susceptibility to parental (versus peer) influences is higher than in families with less warm relations. We hypothesized that in families in which the solidarity pattern is underlined by positive affect (amicable and harmonious), the relation between parental rejection and child attachment insecurity will be stronger than in families with disharmonious (conflicted), detached, or ambivalent solidarity patterns (Susceptibility Hypothesis). Through combination of attachment, family solidarity, and IPARTheory approaches we hope to bridge the gap among largely separate lines of research studying the same, or interrelated processes by integrating different theoretical perspectives, terminology, and instruments.

\section{Method}

\section{Sample}

The study was part of the cross-cultural project "Value of Children and Intergenerational Relations" (VOC study; Trommsdorff \& Nauck, 2005). This was a three-generation study including adolescents, their mothers, maternal grandmothers, and in some national-subsamples, also fathers (among which data from fathers were available for analysis only in Poland) conducted up to date in 16 nations.

The Polish VOC sample was collected between 2006-2009 in urban and rural regions of South-East, North-East, South-West, and North-West Poland and consisted of 575 families with mothers and adolescent children (between the ages of 14 and 17). Due to missing data related with missing responses in scales of our interest only 570 families were analyzed in the present study. Within this sample, data from 290 fathers and adolescents reporting on parenting of fathers were 
collected during the second wave of sampling in 2008-2009 in all country-regions except NorthWestern Poland ( $n=97$ in South-East, $n=97$ in North-East, and $n=96$ in South-West). The mean age of respondents was $15.16(S D=1.34)$ for adolescents, $43.06(S D=5.24)$ for mothers, and 45.25 $(S D=5.23)$ for fathers. Males constituted $40 \%$ of the adolescent sample. Average economic status of the family was $3.14(S D=.64)$ as reported by adolescents, and $2.98(S D=.73)$ as reported by their parents in the range of 1 (low economic status) to 5 (upper economic status). The mean education level of respondents as indicated by completed years of schooling was: $14.29(S D=3.18)$ for mothers, $14.08(S D=3.05)$ for fathers, and $8.49(S D=1.45)$ for adolescents.

\section{Procedure}

Mothers and fathers were surveyed using structured interviews by trained interviewers. Selfreports were used to collect data from adolescents. The interviews lasted between 60 and 90 minutes and were carried out mostly at the homes of the respondents or in locations indicated by respondents.

\section{Measures}

Individual economic status. Participants answered the question about their economic status compared to others using a 5-point Likert scale from (1) "low" to (5) "upper." We averaged the score from reports of mothers (556 reports), fathers (273 reports) and their children (546 reports).

Attachment. We employed the Adult Attachment Scale (Collins \& Read, 1990), referring to a general (not relationship specific) perception of attachment indicated by the dimensions of anxiety, closeness, and dependence (alphas of .78, .78, and .66, respectively). Adolescents rated their attachment using a 5-point Likert scale ranging from (1) indicating low to (5) indicating high levels of agreement. Anxiety relates to worry of abandonment, or doubts about availability of others in times of need (e.g., "People are never there when you need them"). Closeness indicates (dis)comfort being close with others (e.g., "I am comfortable when others depend on me," or "I am somewhat uncomfortable being close to others" for reverse-coded item), whereas dependence refers to confidence in the dependability on others (e.g., "It is easy for me to depend on others," or "I find 
it difficult to trust others completely" for reverse-coded item). High levels of closeness and dependence indicate low levels of attachment avoidance, and low levels of attachment anxiety and avoidance (high closeness and dependence) indicate secure attachment.

Parenting. We used the Parental Acceptance-Rejection Questionnaire (e.g., Rohner, Rohner \& Roll, 1980) to assess parenting quality as perceived by adolescents. Adolescents evaluated parenting of mother (574 reports) and father (290 reports) on a 4-point Likert scale ranging from (1) "almost never true" to (4) "almost always true." The measure is composed of two commonly used subscales: Acceptance and Rejection. Acceptance (alphas: .88 for maternal, and .94 for paternal acceptance) refers to the child's perception of the parent as gentle, supportive and responsive to child emotional states (e.g., "My mother/father makes it easy for me to confide in her/him"). Rejection (alphas: .84 for maternal, and .90 for paternal rejection) indicates parental neglect, aggression and hostility (e.g., "My mother/father goes out of her/his way to hurt my feelings"). Both dimensions are often combined into one warmth dimension, however, our previous studies (e.g., Lubiewska et al., 2016) revealed differences in the relation of acceptance and rejection with adolescents' attachment across cultures. Thus, we analyzed both dimensions separately in the present study. Although parents and adolescents reported their parenting acceptance in the VOC study, only adolescents were asked about parenting rejection of parents. Therefore, we used only data collected from adolescents in the present study.

Quality of relationship. Parent-child relations were assessed with the Network of Relationship Inventory developed by Furman and Buhrmester (1985). Adolescents reported the frequency of behaviors in relation with mother and father by using a 5-point Likert scale ranging from (1) "never" to (5) “always." Three subscales were assessed: Intimacy (e.g., "How often do you share your secrets and private feelings with your mother/father?"), admiration (e.g., "How often does your mother/father let you know that you're good at many things?"), and conflict (e.g., "How often do you and your mother/father disagree and quarrel?"). Subscales consisted of three items each. Intimacy and admiration subscales were collapsed to assess affectual solidarity in our study. 
All items were formulated separately to measure quality of relationship with mother (alphas: .87 and .86 for affectual solidarity and conflict, respectively) and father (alphas: .88 and .89 for affectual solidarity and conflict, respectively).

Family values. We used Georgas' (1991) Family Values Scale consisting of seven items assessing responsibilities of children toward family and relatives (e.g., "Children should obey their parents”), and responsibilities of parents toward children (e.g., "A family’s problems should be solved within the family"). Mothers, fathers, and their children rated the strength of their agreement on a 5-point Likert scale ranging from (1) "strongly disagree" to (5) "strongly agree." All items were used as one family value dimension for the main analyses (alphas: .65, .71, and .64, for mothers, fathers, and adolescents, respectively).

Emotional support given by adolescent child to mother and father. The three following items developed for the VOC study were used to assess the frequency of Adolescent-to-parent emotional support (alphas: .79 and .78, for mother-support and father-support, respectively) in our study: "How often do you give advice to your father/mother?"; "How often do you try to comfort your mother/father?"; and "How often do you talk to your father/mother about his/her worries or sorrows?" Adolescents used a 5-point Likert scale ranging from (1) "never" to (5) "always" to assess the frequency of their emotional support given to mother and father.

\section{Data Analyses}

We carried out a cluster analysis aiming to distinguish different family patterns. Four dimensions of intergenerational solidarity were used to group families into distinct patterns of intergenerational relations. (1) Consensual solidarity was assessed by parent-child consensus in family values (a raw mean difference of each of seven family value items in child-parent dyads averaged first across mother-child and father-child dyads following the formula $\frac{\sum_{i j}\left|F V_{\text {adol. }}-F V_{\text {parent }}\right|}{7}$, and then averaged across parents-child dyads). The resulting family values consensus index ranged from 0 to 3.43 and absolute values more distant from zero indicate low family value consensus. As 
our primary interest in the present study was to assess parent-child similarity (consensus) in family values we did not analyze the level of values endorsement. Thus the family solidarity index used in our study does not inform whether both, the parent and the child had high or low scores of family values.

Furthermore, as measures of affectual, functional solidarity (support), and conflict used in the VOC study assessed parent-child relations from the perspective of children reporting on their parents (adolescents on their parents and parents on their own parents), we used only data from adolescents for our analyses. (2) Affectual solidarity was indicated by a mean score of intimacy and admiration perceived by adolescent in his/her relation with mother and father averaged across parents. (3) Conflict was defined as the mean score of adolescent-mother and adolescent-father conflict reported by adolescents. (4) Adolescent-to-parents emotional support was indicated by a mean score of child-to-mother and child-to-father support.

We computed model-based cluster analysis (Latent Class Analysis, LCA) using the 'mclust' R package (Fraley \& Raferty, 2003) to identify patterns of family solidarity using the four family solidarity dimensions described above. Model-based cluster analysis tests the fit of models that differ in the specification of cluster characteristics. The classification is based on membership probabilities and provides statistical criteria for establishing the number of latent classes, based on the Bayesian Information Criterion (BIC) and Log-likelihood (LL) indices. We determined the number of clusters by the best fitting model identified by the clustering procedure, as defined by the BIC. The sequential likelihood ratio test based on bootstrapping method to obtain $p$-values for differences between compared models (BLRT) was used to choose the between alternative clustersolutions (Nylund, Asparouhov, \& Muthen, 2007). The BLRT index indicates that the $\mathrm{K}_{0}$-class model provides significantly better fit to the observed data than the $\mathrm{K}_{-1}$-class model. Summarizing family patterns found in our study we reported mean differences in solidarity dimensions, and parenting and attachment components not used to cluster families. 
To analyze the link between parenting and adolescent attachment across different family patterns, we carried out moderation analyses. We tested two hierarchical regression models for each of the three attachment dimensions. The analyses for mothers and fathers were separated due to strong sample differences, but also to avoid problems related with high collinearity of predictors (see Table 1), and to increase the probability of detecting significant effects of fathers.

Demographic variables (adolescent gender, age, economic status of the family) and the family pattern were entered in step 1, maternal (Model 1) or paternal (Model 2) parenting dimensions were entered in step 2, and interaction between parenting and solidarity patterns were entered in step 3 . Parenting variables were centered prior to the analysis and family patterns were dummy codded into three variables (D1-D3) with the Harmonious pattern as the reference group (code 1 was assigned to patterns: amicable in D1, detached in D2, and disharmonious in $\mathrm{D} 3$, whereas other patterns were coded as zero, e.g., if an individual was classified to other than amicable cluster in D1 variable, zero was assigned; for visualization of simple slopes, regression line for the reference group was also retrieved).

\section{Results}

\section{Patterns of Family Solidarity in Adolescent-Parent Relations}

LCA indicated the 3- and 4-cluster models as the most optimal with the BIC values of 4627.589 and -4625.348, respectively. The differences between 4-cluster model and 3-cluster model was significant indicating that 4 -cluster model is preferred over 3 -cluster model $\left(\mathrm{BLRT}_{3 \text { vs } 4}=\right.$ 40.367; $p<.001)$. The difference between 4 - and 5-cluster model was not significant $\left(\mathrm{BLRT}_{4}\right.$ vs $5=$ $10.336 ; n s$ ) indicating that four clusters are sufficient (more parsimonious than five clusters) in splitting the sample into subgroups differing by the pattern of family solidarity indicators. The Log Likelihood value of 4-cluster model was -2211.004. Clusters' characteristics and density parameters are reported in Table 2.

Regarding our research question the four clusters could be described similar to those patterns reported in studies with adult children. The distribution of the patterns was as follows: $51 \%$ 
of families showed a negative family climate with $32.6 \%$ classified as detached and $18.2 \%$ as disharmonious. Furthermore, within the positive family climate, more families revealed harmonious (31.8\%) than amicable (17.4\%) patterns (see Table 2). Adolescents in disharmonious families were six months older than adolescents in harmonious family pattern. Girls were more represented than boys in disharmonious and amicable families, compared to other family clusters, $\chi^{2}(3,570)=$ 9.809; $p<.050$.

The four family types found in our study differed by all solidarity components of: Family values consensus, $F(3,569)=4.89, p=.002$; affect, $F(3,569)=166.38, p<.001$; conflict, $F(3$, $569)=112.92, p<.001 ;$ and adolescent-to-parent emotional support, $F(3,569)=316.43, p<.001$. The amicable pattern showed the highest affectual solidarity, emotional support given by adolescent to parents, high family value consensus, and low parents-child conflict. The harmonious pattern was similar to the amicable type, however, the affectual component, adolescents-to-parents emotional support, and family value consensus were lower than in the amicable type. The detached pattern showed low values in all solidarity components (affect, conflict, emotional support to parents, and family value consensus). Finally, the disharmonious pattern can be described in terms of relatively high conflict, family value parents-child dissimilarity, low affectual parents-child intimacy, and low adolescents' support given to parents.

Analyzing differences between all patterns through the lens of composite dimensions, several differences deserve attention (see Table 3). First, parents-child differences in the level of family values revealed opposite patterns in detached and disharmonious, as compared to amicable and harmonious families. In the first two, parents reported higher levels of family values than their children (positive values in Table 3), whereas in the last two patterns of families, children reported higher family values than their parents (negative values in Table 3). Affectual solidarity (intimacy and admiration) was relatively the lowest in disharmonious and detached families. High conflict distinguished disharmonious from other types of families. Moreover, the frequent emotional support given by adolescents to parents differentiated amicable from harmonious families. 


\section{Relations Between Parenting Acceptance, Rejection, and Adolescents' Attachment Across Family Solidarity Patterns}

First, we looked at mean differences in parenting and attachment dimensions across family solidarity patterns (see Table 3). General attachment representation of adolescents differed across solidarity patterns only with regard to higher dependence in harmonious than in disharmonious families, $F(3,569)=3.47, p<.05 \mathrm{We}$ also found differences for parenting dimensions. Rejection of mothers, $F(3,569)=13.04, p<.001$, and fathers, $F(3,289)=9.25, p<.001$, was higher in disharmonious than in other family patterns. Acceptance of mothers, $F(3,569)=60.46, p<.001$, and fathers $F(3,289)=39.74, p<.001$, was higher in amicable and harmonious families than in detached and disharmonious families.

Our main results testing the Susceptibility Hypothesis revealed that in general, maternal and paternal rejection (but not acceptance) yielded to be significantly weak or moderate predictors of child attachment insecurity (see Table 4). In line with our expectations, the regression analyses showed that relations between parental rejection and adolescents' anxiety and closeness were moderated by the type of family solidarity (see Table 4, step 3). In particular, as visualized in Figure 1 (two upper panels), both links between maternal rejection and adolescents' closeness, as well as between maternal rejection and adolescents' anxiety, were stronger in harmonious than in detached families. It is worth noting that in detached families, maternal rejection was not related with adolescents' attachment anxiety. These results partly supported our Susceptibility Hypothesis. However, not in line with this hypothesis, we found that the paternal rejection-closeness link was the strongest in amicable families and the weakest in harmonious families (see Table 4 and Figure 1, lower panel). We did not find any moderation effect of family type for parental acceptance.

\section{Discussion}

We set out in the present study to test the relation between parenting perceived by adolescents and their general attachment in the context of family solidarity patterns. In line with expectations related with our research question, the results revealed similar solidarity types in 
families of adolescents as reported in studies with adult children and their parents, though with different distributions; and partly confirmed the Susceptibility Hypothesis assuming differences in parenting-attachment link across family types.

\section{Family Solidarity Patterns in Adolescence}

In line with studies on adult children and their elderly parents, we found in our study amicable, harmonious (close/steady), disharmonious and detached (distant, civil) patterns of families. Yet, few differences in family pattern distributions of families of adolescents compared to adult children resulted from our study. First, detached family pattern was one of the most frequently displayed in our study (33\%). Then, a smaller group of adolescent's families was categorized as amicable and harmonious than the range of these family patterns found in adult child-parent relations (17\% vs. $22-68 \%$ and $32 \%$ vs. $40-47 \%$, respectively). Finally, we did not find an ambivalent family pattern. Although these differences may be related with categorization of families into distinct patterns using data not only from mother-child dyads (as in other studies) but also including father-child relations, the developmental explanations seem to be also viable.

Striving for autonomy while maintaining relatedness is an indicator of attachment security of adolescents in relation with their parents (Allen et al., 2007). Capitalizing on previous family experiences (Oudekerk et al., 2015) and other individual and contextual factors, adolescents are going differently through this process. The four patterns of family relations found in our study may reflect these differences and underlie pattern distributions in our study. In two among four family solidarity patterns, the balance between autonomy and relatedness seems to be less present than in others. Relatedness appears to be prevalent in amicable families, whereas autonomy in detached families. Balancing between autonomy and relatedness seems to be more supported in harmonious and disharmonious families. In harmonious families, prevalence of affect over conflict revealed in our study may be indicative for autonomy negotiation through discussion of disagreements, rather than through conflicts (Allen et al., 2003). In disharmonious families, conflict is represented more than affect, but emotional support seems to be also maintained. Conflicts may strengthen parent- 
child relationship and may be a way to negotiate autonomy (Laursen \& Collins, 2009). Yet, the anger associated with parent-child conflicts may channel adaptive or maladaptive outcomes. Based on our study we cannot conclude to what extent conflict in disharmonious families is adaptive or not.

Furthermore, girls compared to boys were more often classified into disharmonious and amicable than into detached and harmonious family patterns. It seems possible that the developmental pathway of girls in adolescence may be marked by conflict (disharmonious families) or by high intimacy and emotional support toward parents (amicable families). Different from girls, family climate of boys may be more characterized by detachment or balance between affect and conflict. Moreover, we found that adolescents in disharmonious family pattern were in average six months older than in harmonious families. This age difference seems not to be large but it is possible that it may reflect developmental dynamics of identity conflicts in adolescence.

Even though the amicable pattern is conceived as very frequent and the most optimal in adult child-parent relations, it was found less frequent in our study. Regarding characteristics of adolescent-parent relation where adolescents are still recipients of care rather than care-providers (e.g., Carlivati \& Collins, 2007), it shall be considered whether very frequent child-to-parents emotional support found in amicable families is the optimal context for adolescents' development. Providing emotional support toward parents may be hindering adolescents' autonomy negotiations and be indicative for partial role-reversal in a parent-child relation (Macfie et al., 2008).

Finally, we did not find an ambivalent pattern of families in our study, although the same processes typical for adolescence may be expected to result in simultaneously high intimacy and conflict between adolescents and their parents. This finding seems to contradict not only studies on adult child-parent family patterns, but also scant studies on adolescents' family relations. To our knowledge, the only study on adolescents' ambivalence was carried out by Tighe and colleagues (2016) who evidenced feelings of ambivalence in adolescence. Our study provides weak support for such a conclusion. At least two methodological differences may partly explain this inconsistency 
between these two studies: varying ambivalence assessment strategies used in both studies (positive and negative components compared separately in our study versus assessed through the ambivalence formula); and ambivalence assessment at the individual level (Tighe et al., 2016) or the level of family pattern (used in our study). The variability in individual-level ambivalence may be higher for adolescent than for adult children watering down the family-level ambivalence in our study.

\section{Relations Between Parenting and Attachment Across Family Patterns}

Regardless of the context of family pattern, results of our study revealed that adolescents' perception of maternal and paternal rejection were predictors of child anxiety, dependence, and discomfort in closeness. This finding is in line with previous studies revealing that rejection is an important predictor of attachment insecurity in adolescence (e.g., Casselman \& McKenzie, 2015). Furthermore, in line with previous studies (e.g., Allen et al., 2007) on paternal relationship qualities, parenting of fathers in our study was found as less strongly related to adolescents' attachment than maternal parenting. The main goal of our study focused on the hypothesis that adolescents from families with more (versus less) positive family climate will be more susceptible to parenting influences. The hypothesis was confirmed for the relation of adolescents with mothers and partly for the relation with fathers.

Maternal parenting and attachment across family patterns. Maternal rejection in our study was more strongly related with adolescents' closeness and anxiety in harmonious and amicable than in other types of families. This finding adds to studies indicating that adolescents in warm families are more susceptible to family influences (Laursen \& Collins, 2009), including attachment-related outcomes, and that the mother-child relation is an important, although moderate, predictor of attachment in adolescence (e.g., Allen et al., 2003; Laursen \& Collins, 2009). It is worth noting that in both types of families with positive climate, adolescents perceived their own parents as more accepting than in families with negative climate, but did not differ in the level of attachment security dimensions (with exception of dependence higher in harmonious than in 
disharmonious families). It is possible that adolescents' turning toward peers may buffer the adverse effects of negative family climate on their attachment security (Sentse, Lindenberg, Omvlee, Ormel, \& Veenstra, 2010). However, further studies are needed to test this hypothesis. Furthermore, lack of differences in the level of general attachment quality of adolescents across family patterns in comparison with varying parenting and solidarity components may be related with developmental origins and adaptive function of both domains. Pattern of family relations (level of solidarity components) as well as parenting acceptance and rejection investigated in our study reflect the quality of relations between the child and his/her parents in adolescence. Attachment quality develops since child birth and is relatively stable in time (e.g., Fraley, 2002). Thus, the effect of family solidarity patterns on general (not relation-specific) attachment quality captured in adolescence may be overall rather a weak than a strong effect. Nonetheless, such effects could set up pathways that may lead to stronger consequences for attachment quality over time. This study revealed how current proximal family-related context of child development affected the dynamics of adolescent attachment.

Paternal parenting and attachment across family patterns. Although the strength of relation between maternal rejection and child attachment was highly comparable in amicable and harmonious families, our analyses revealed a significant difference in how rejection of fathers predicts attachment in these two types of families. The link between paternal rejection and adolescents' closeness was significant in amicable families (and in other family types), and not significant in harmonious families. As such, this finding is not in line with our hypothesis assuming stronger parenting-attachment link in families with positive than negative climate. Yet, it seems to correspond with findings from studies indicating different effects of the quality of relationship with mother and father in adolescence. For example, even though the quality of maternal parenting is a strong predictor of adolescents' attachment security, only rejection of fathers (Casselman \& McKenzie, 2015) and their use of harsh conflict tactics (Allen et al., 2007) were found as significant additional predictors of emotional deregulation and attachment security of adolescent children. 
Opposite effects of the quality of relation with mother and father were also evidenced. In their longitudinal study, Tighe and colleagues (2016) found that ambivalence toward mothers was related with adolescents' depressive symptoms, however, ambivalence toward fathers was related with a decline of these symptoms.

Interpreting our findings, we propose to stress that the relation with mothers in adolescence maintains more closeness and is based on nurturance and disclosure than the relation with fathers with whom adolescents consult money and power issues more frequently (Laursen \& Collins, 2009; Markiewicz et al., 2006). Thus, the relation with fathers may be the first in which adolescents are experimenting with their autonomy negotiations. In harmonious families, parents and children may be able to maintain and reaffirm their relationship while disagreeing, therefore avoiding decrease in attachment security of adolescents and supporting their capacity to balance autonomy and relatedness across relationships (Allen et al., 2003; Allen et al., 2007). It is possible that if adolescents are successful in autonomy negotiations with fathers, they may handle paternal rejecting behaviors differently (Rohner, 2016). Specifically, paternal rejection may be interpreted by adolescents as triggered by their autonomy strivings, therefore perceived as less severe than paternal rejection in amicable families, where adolescents seem to maintain relatedness more than strive for autonomy. Thus, paternal rejection in amicable families may severely undermine adolescents' comfort in closeness across relations having any effect in harmonious families. The result of the study by Tighe and colleagues (2016) on positive effects of child-to-father ambivalence on depressive symptoms of adolescents seems to be underlined by similar processes. The finding of our study may indicate that the relation with fathers in adolescence becomes the training field for autonomy negotiations, which is fostered by warm family climate accessible in harmonious more than in amicable families.

\section{Limitations}

The study has several limitations. First, even though we believe that child interpretation of parenting rather than the objective parenting behaviors affect their self-other models more, 
behavioral indicators and longitudinal design are lacking in our study. Including father-child data to our classification provided a more complex picture of family relations. However, this strategy limits comparisons with previous studies targeting the solidarity-conflict model. Furthermore, comparisons of the distribution of the family patterns with previous studies is limited partly due to varying types of cluster analyses and partly to the wide range of some of the patterns for adult children studies (e.g., $22 \%$ to $68 \%$ for amicable pattern). It is worth noting however that although different clustering methods were used across studies similar results have been found supporting validity of four-cluster perspective on family solidarity model. Moreover, consensual solidarity index was analyzed in our study only with regard to adolescent-parent similarity in family values. The level of family values themselves was not of primary interest (e.g., see Trommsdorff \& Mayer, 2012), and not analyzed further which may limit possible conclusions. Another limitation of this study is the smaller sample size of adolescents reporting about parenting of fathers and fathers reporting on their family values compared to respective data regarding mothers. As a result, different patterns might occur when only data from mothers, fathers, or from both in equal size were used to cluster families. It is also possible that our clustering would be different when solidarity indicators used in previous studies were analyzed. Conclusions of our study might be also diverse if we investigate other than four-cluster solution. Finally, the power of testing the susceptibility hypotheses analyzed in our study was also limited by the relatively low within-cluster sample sizes; further the reliability of the instruments was not perfect. These limitations only allow for a preliminary speculative discussion.

\section{Conclusions}

The solidarity model can be applied to characterize family climate in adolescent-parent relations while role-reversal has a different meaning in amicable families of adolescents than of adult offspring. The family solidarity model can be useful in explaining susceptibility of adolescents' attachment representations to parental influences as indicated in the IPARTheory. By using a person-centered approach we added to studies testing the meaning of affectual solidarity in 
parent-adolescent relations and we evidenced the usefulness of the solidarity model beyond adult child-parent relations. We hope that our study to some extent bridges the gap between separate research traditions on attachment, IPARTheory, and family solidarity.
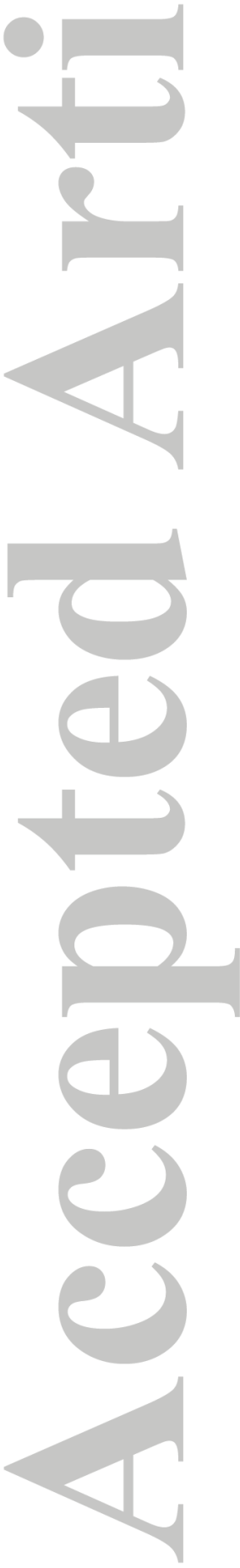


\section{References}

Ackerman, R. A., Kashy, D. A., Donnellan, M. B., Neppl, T., Lorenz, F. O., \& Conger, R. D.

(2013). The interpersonal legacy of a positive family climate in adolescence. Psychological Science, 24, 243-250. doi: 10.1177/0956797612447818

Ainsworth, M. D. S., Blehar, M., Waters, E., \& Wall, S. (1978). Patterns of attachment: A psychological study of the Strange Situation. Hillsdale, NJ: Erlbaum.

Albert, I., Ferring, D., \& Michels, T. (2013). Intergenerational family relations in Luxembourg. Family values and intergenerational solidarity in Portuguese Immigrant and Luxembourgish families. European Psychologist, 18, 59-69. doi: 10.1027/1016-9040/a000125

Allen, J. P., \& Manning, N. (2007). From safety to affect regulation: Attachment from the vantage point of adolescence. New Directions for Child and Adolescent Development, 117, 23-39. doi: $10.1002 / \mathrm{cd} .192$

Allen, J. P., McElhaney, K. B., Land, D. J., Kuperminc, G. P., Moore, C. W., O’Beirne-Kelly, \& Kilmer, S. L. (2003). A secure base in adolescence: Markers of attachment security in the mother-adolescent relationship. Child Development, 74, 292-307. doi: 10.1111/14678624.t01-1-00536

Allen, J. P., Porter, M., McFarland, C., McElhaney, K. B., \& Marsh, P. (2007). The relation of attachment security to adolescents' paternal and peer relationships, depression, and externalizing behavior. Child Development, 78, 1222-1239. doi: 10.1111/j.14678624.2007.01062.x

Allen, J. G., Stein, H., Fonagy, P., Fultz, J., \& Target, M. (2005). Rethinking adult attachment: A study of expert consensus. Bulletin of the Menninger Clinic, 69, 59-80. doi: 10.1521/bumc.69.1.59.62266

Anthony, E. K., \& Stone, S. I. (2010). Individual and contextual correlated of adolescent health and well-being. Families in Society, 91, 225-233. doi: 10.1606/1044-3894.3999 
Attar-Schwartz, S. (2015). Emotional closeness to parents and grandparents: A moderated mediation model predicting adolescent adjustment. American Journal of Orthopsychiatry, 85, 495-503. doi: 10.1037/ort0000082

Belsky, J., Jaffee, S. R., Caspi, A., \& Moffitt, T. (2003). Intergenerational relationships in young adulthood and their life course, mental health, and personality correlates. Journal of Family Psychology, 17, 460-471. doi: 10.1037/0893-3200.17.4.460

Belsky, J., Jaffee, S. R., Hsieh, K.-H., \& Silva, P. A. (2001). Child-rearing antecedents of intergenerational relations in young adulthood: A prospective study. Developmental Psychology, 37, 801-813. doi: 10.1037//0012-1649.37.6.801

Bengtson, V. L. (2001). Beyond the nuclear family: The increasing importance of multigenerational bonds. Journal of Marriage and Family, 63, 1-16. doi: 10.1111/j.1741-3737.2001.00001.x

Bengtson, V. L., \& Schrader, S. (1982). Parent-child relations. In D. Mangen \& W. A. Peterson (Eds.), Research instruments in social gerontology (Vol. 2, pp. 115-186). Minneapolis, MN: University of Minnesota Press.

Bergman, L. R. (2001). A person approach in research on adolescence: Some methodological challenges. Journal of Adolescent Research, 16, 28-53. doi: 10.1177/0743558401161004

Carlivati, J., \& Collins, W. A. (2007). Adolescent attachment representations and development in a risk sample. New Directions for Child and Adolescent Development, 117, 91-106. doi: $10.1002 / \mathrm{cd} .196$

Casselman, R. B., \& McKenzie, M. D. (2015). Young adults' recollections of parental rejection and self-reported aggression : The mediating roles of insecure adult attachment and emotional dysregulation. Journal of Child \& Adolescent Trauma, 8, 61-71. doi: 10.1007/s40653-014$0032-x$

Collins, N. L., \& Read, J. R. (1990). Adult attachment, working models, and relationship quality in dating couples. Journal of Personality and Social Psychology, 58, 644-663. doi: 10.1037/0022-3514.58.4.644 
Cortina, M., \& Liotti, G. (2010). Attachment is about safety and protection, intersubjectivity is about sharing and social understanding. Psychoanalytic Psychology, 27, 410-441. doi: $10.1037 / \mathrm{a} 0019510$

De Wolff, M. S., \& van IJzendoorn, M. H. (1997). Sensitivity and attachment: A meta-analysis on parental antecedents of infant attachment. Child Development, 68(4), 571-591. doi: $10.2307 / 1132107$

Doyle, A. B., Lawford, H. L., \& Markiewicz, D. (2009). Attachment style with mother, father, best friend, and romantic partner during adolescence. Journal of Research on Adolecence, 19, 690-714. doi: 10.1111/j.1532-7795.2009.00617.x

Fasang, A. E., \& Raab, M. (2014). Beyond transmission: Intergenerational patterns of family formation among middle-class American families. Demography, 51, 1703-1728. doi: $10.1007 / \mathrm{s} 13524-014-0322-9$

Ferring, D., Michels, T., Boll, T., \& Filipp, S.-H. (2009). Emotional relationship quality of adult children with ageing parents: on solidarity, conflict and ambivalence. European Journal of Ageing, 6, 253-265. doi: 10.1007/s10433-009-0133-9

Fraley, R. C. (2002). Attachment stability from infancy to adulthood: Meta-analysis and dynamic modelling of developmental mechanisms. Personality and Social Psychology Review, 6, 123-151. doi: 10.1207/S15327957PSPR0602_03

Fraley, R. C., \& Raftery, A. E. (2003). Enhanced model-based clustering density estimation and discriminant analysis software: MCLUST. Journal of Classification, 20, 263-286. doi: 10.1007/s00357-003-0015-3

Friedlmeier, W., \& Lubiewska, K. (2012, March). Intergenerational solidarity and life satisfaction in middle-aged daughters and mothers in Poland and USA. Paper presented at the Value of Children and Intergenerational Relations workshop in Konstanz, Germany. 
Furman, W., \& Buhrmester, D. (1985). Children's perceptions of the personal relationships in their Social networks. Developmental Psychology, 21, 1016-1024. doi: 10.1037/00121649.21.6.1016

Furman, W., \& Buhrmester, D. (2009). The Network of Relationships Inventory: Behavioral Systems Version. International Journal of Behavioral Development, 33, 470-478. doi: $10.1177 / 0165025409342634$

Georgas, J. (1991). Intrafamily acculturation of values in Greece. Journal of Cross-Cultural Psychology, 22, 445-457. doi: 10.1177/0022022191224001

Giarrusso, R., Silverstein, M., Gans, D., \& Bengtson, V. L. (2005). Ageing parents and adult children: New perspectives on intergenerational relationships. In M. L. Johnson, V. L. Bengtson, P. G Coleman \& T. B. L. Kirkwood, (Eds.), Cambridge handbook of age and ageing (pp. 413-421). London, UK: Cambridge University Press.

Hinnen, C., Sanderman, R., \& Sprangers, M. A. G. (2009). Adult attachment as mediator between recollections of childhood and satisfaction with life. Clinical Psychology and Psychotherapy, 16, 10-21. doi: 10.1002/cpp.600

Hughes, M. M., Blom, M., Rohner, R. P., \& Britner, P. A. (2005). Bridging acceptance-rejection theory and attachment theory in the preschool Strange Situation. Ethos, 33, 378-401. doi: 10.1525/eth.2005.33.3.378

Katz, R., Lowenstein, A., Phillips, J., \& Daatland, S. O. (2005). Theorizing intergenerational family relations. Solidarity, conflict, and ambivalence in cross-national contexts. In V. L. Bengston, A. C. Acock, K. R., Allen, P. Dilworth-Anderson \& D. M. Klein (Eds.). Sourcebook of family theory and research (pp. 393-407). Thousand Oaks, CA: Sage.

Laursen, B., \& Collins, W. A. (2009). Parent-child relationships during adolescence. In R. M. Lerner \& L. Steinberg (Eds.), Handbook of adolescent psychology, Volume 2: Contextual influences on adolescent development (3rd edition) (pp. 3-42). New York, NY: Wiley. 
Lubiewska, K., Mayer, B., Albert, I., \& Trommsdorff, G. (2016). Relations between parenting and adolescents' attachment in diverse cultures. Manuscript submitted for publication.

Macfie, J., Fitzpatrick, K. L., Rivas, E. M., \& Cox, M. J. (2008). Independent influences upon mother-toddler role reversal: Infant-mother attachment disorganization and role reversal in mother's childhood. Attachment \& Human Development, 10, 29-39. doi:

\section{$10.1080 / 14616730701868589$}

Markiewicz, D., Lawford, H. L., Doyle, A. B., \& Haggart, N. (2006). Developmental differences in adolescents' and young adults' use of mothers, fathers, best friends, and romantic partners to fulfill attachment needs. Journal of Youth and Adolescence, 35, 121-134. doi:

10.1007/s10964-005-9014-5

Merz, E.-M., Schuengel, C., \& Schulze, H.-J. (2007). Intergenerational solidarity: An attachment perspective. Journal of Aging Studies, 21, 175-186. doi: 10.1016/j.jaging.2006.07.001

Michels, T., Albert, I., \& Ferring, D. (2011). Emotional relations with grandparents and received support: The adolescent view. Journal of Intergenerational Relationships, 9, 264-280. doi: $10.1080 / 15350770.2011 .593435$

Mikulincer, M., \& Shaver, P. R. (2007). Attachment in adulthood. Structure, dynamics, and change. New York, NY: The Guilford Press.

Nauck, B. (2014). Affection and conflict in intergenerational relationships of women in sixteen areas in Asia, Africa, Europe, and America. Comparative Population Studies, 39, 647-678. doi: $10.12765 / \mathrm{CPoS}-2014-16 \mathrm{en}$

Nylund, K. L., Asparouhov, T., \& Muthén, B. O. (2007). Deciding on the number of classes in Latent Class Analysis and Growth Mixture Modeling: A Monte Carlo simulation study. Structural Equation Modeling, 14, 535-569. doi: 10.1080/10705510701575396

Olson, D. H. (2000). Circumplex model of marital and family systems. Journal of Family Therapy, 22, 144-167. doi: 10.1111/1467-6427.00144 
Oudekerk, B. A., Allen, J. P., Hafen, C. A., Hessel, E. T., Szwedo, D. E., \& Spilker, A. (2013). Maternal and paternal psychological control as moderators of the link between peer attitudes and adolescents' risky sexual behaviors. Journal of Early Adolescence, 34, 413-435. doi: 10.1111/cdev.12313.

Oudekerk, B. A., Allen, J. P., Hessel, E. T., \& Molloy, L. E. (2015). The cascading development of autonomy and relatedness from adolescence to adulthood. Child Development, 86, 472-485. doi: $10.1111 /$ cdev.12313

Ratto, N., Doyle, A. B., \& Markiewicz, D. (2016). Attachment with mother and adolescents' conflict with romantic partner or close friend. Canadian Journal of Behavioural Science, 48, 68-77. doi: 10.1037/cbs0000031

Rohner, R. P., (2016). Introduction to Interpersonal Acceptance-Rejection Theory (IPARTheory) and evidence. Online Readings in Psychology and Culture, 6. doi: 10.9707/2307-0919.1055

Rohner, E. C., Rohner, R. P., \& Roll, S. (1980). Perceived parental acceptance-rejection and children's reported behavioral dispositions. A comparative and intracultural study of American and Mexican children. Journal of Cross Cultural Psychology, 11, 213-231. doi: $10.1177 / 0022022180112006$

Schwarz, B., Trommsdorff, G., Albert, I., \& Mayer, B. (2005). Adult parent-child relationships: Relationship quality, support, and reciprocity. Applied Psychology: An International Review, 54, 396-417. doi: 10.1111/j.1464-0597.2005.00217.x

Sentse, M., Lindenberg, S., Omvlee, A., Ormel, J., \& Veenstra, R. (2010). Rejection and acceptance across contexts: Parents and peers as risk and buffers for early adolescent psychopathology. The TRAILS study. Journal of Abnormal Child Psychology, 38, 119-130. doi: $10.1007 / \mathrm{s} 10802-009-9351-\mathrm{z}$

Steinbach, A. (2008). Intergenerational solidarity and ambivalence: Types of relationships in German families. Journal of Comparative Family Studies, 39(1), 115-127. 
Tighe, L. A., Birditt, K. S., \& Antonucci, T. C. (2016). Intergenerational ambivalence in adolescence and early adulthood: Implications for depressive symptoms over time.

Developmental Psychology, 52, 824-834. doi: 0.1037/a0040146

Trommsdorff, G., \& Mayer, B. (2012). A cross-cultural study of intergenerational relations. In H. Bertram \& N. Ehlert (Eds.), Family, ties, and care. Family transformation in a plural modernity (pp. 315-342). Opladen, Germany: Barbara Budrich.

Trommsdorff, G., \& Nauck, B. (Eds.). (2005). The value of children in cross-cultural perspective: Case studies from eight societies. Lengerich, Germany: Pabst.

Williams, L. R., \& Anthony, E. K. (2015). A model of positive family and peer relationships on adolescent functioning. Journal of Child and Family Studies, 24, 658-667. doi:

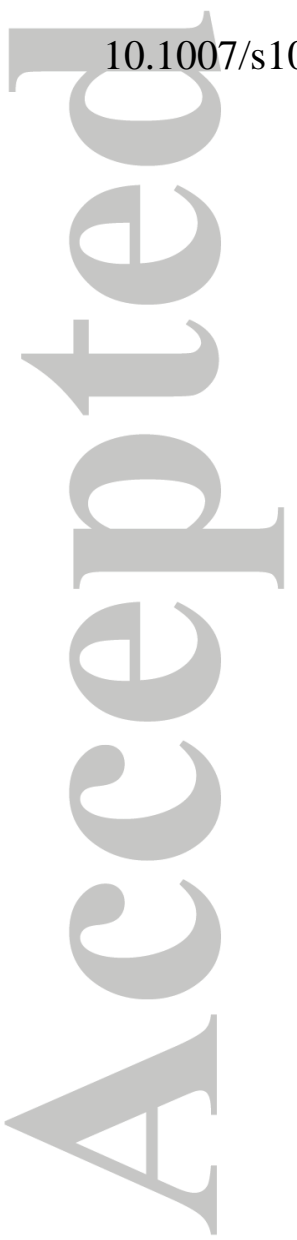


Table 1

Descriptive Statistics and Correlations Between Dimensions of Attachment, Parenting, and Family Solidarity Components

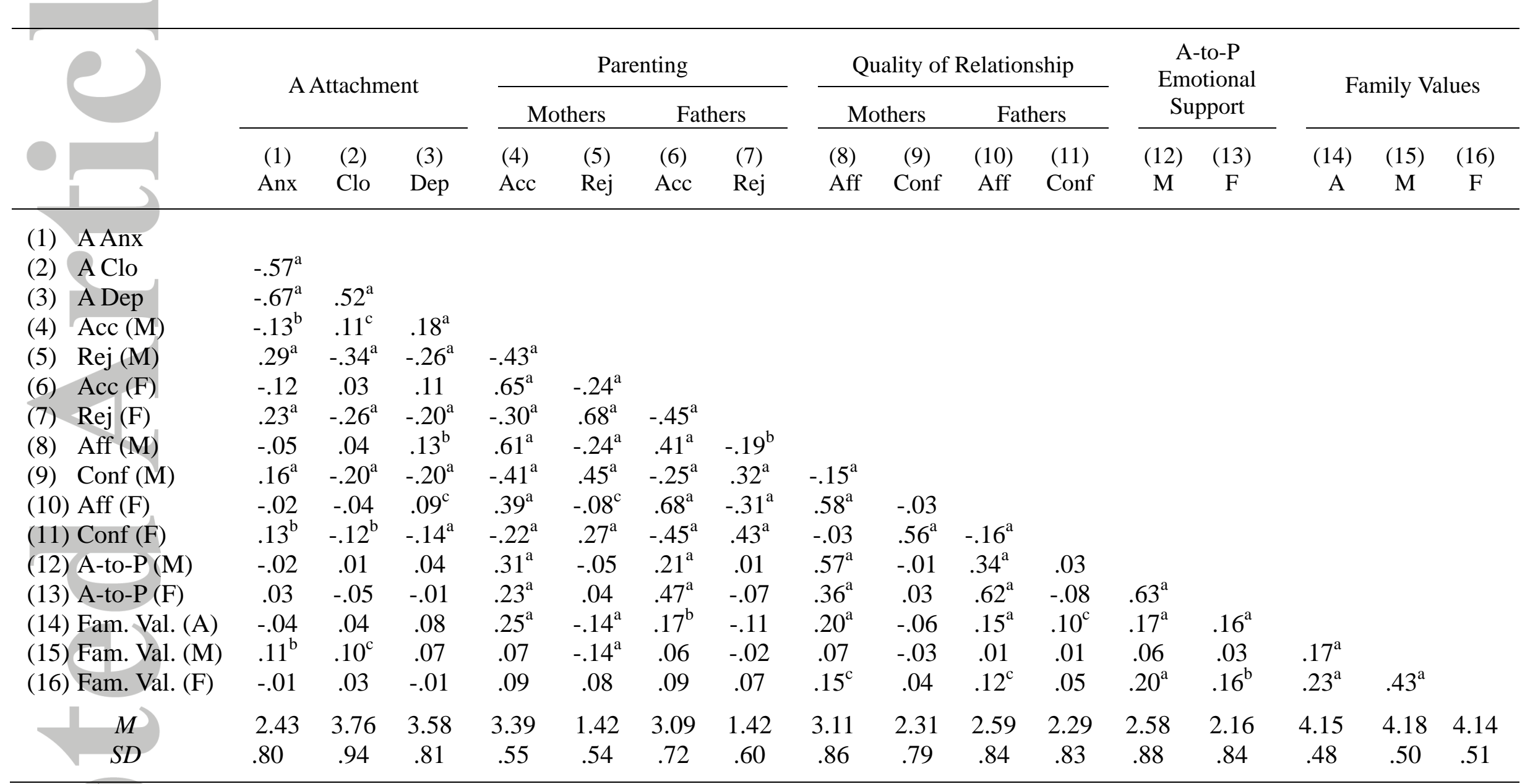

${ }^{\mathrm{c}} p<.05 .{ }^{\mathrm{b}} p<.01 .{ }^{\mathrm{a}} p<.001 . \mathrm{A}-$ adolescents. M-mothers. F-fathers. Anx-anxiety. Clo-closeness. Dep-dependence. Acc-acceptance. Rej-rejection. Aff-affectual solidarity. Conf-conflict. A-to-P-adolescent-to-parents emotional support. Fam. Val-family values. 
Table 2

Description of Family Solidarity Patterns in Adolescent Child-Parents Relations

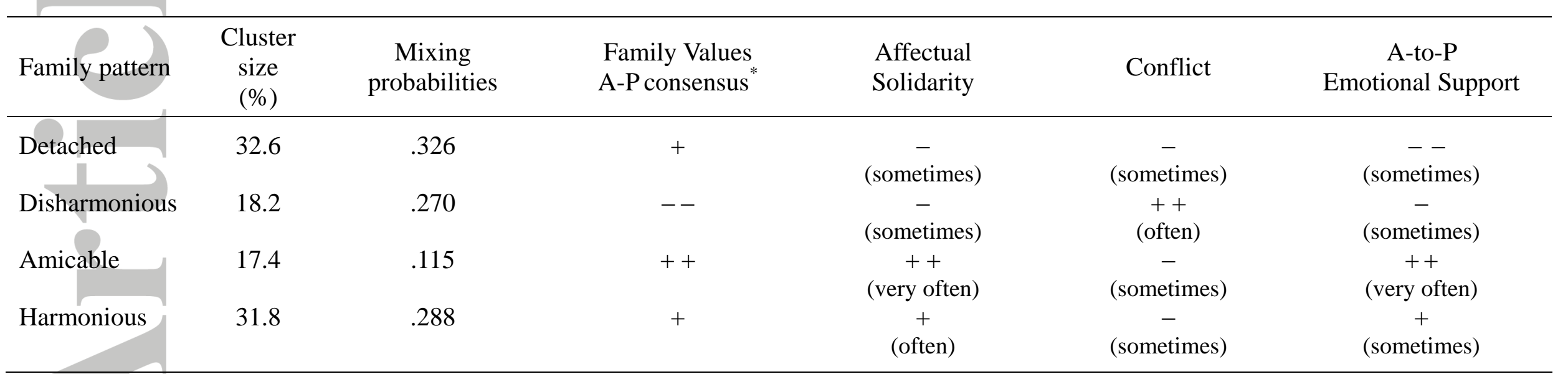

Note. Relative saturation of dimensions based on: (1) ANOVA differences (see Table 3) where ++ indicates very high, + indicates high, - indicates low,

- - indicates relatively very low mean within each component of solidarity compared to the component's mean values in other patterns; (2) Likert

response-scale format (in brackets) indicating the frequency of affect, conflict and support in parents-child relations. ${ }^{*}$ Between-patterns differences in family value consensus are based on relative distance of absolute value of pattern mean from zero (indicating lack of parents-child differences). Aadolescents. P-parents. 
Table 3

Means (SDs) and ANOVA and Chi ${ }^{2}$ Differences Between Adolescents' Age and Gender Distribution, Family Solidarity Components, Parenting, and Adolescents' Attachment Dimensions across Family Solidarity Patterns

\begin{tabular}{|c|c|c|c|c|c|}
\hline \multicolumn{2}{|c|}{ Adolescents-related variables } & $\begin{array}{l}\text { Detached } \\
(n=186)\end{array}$ & $\begin{array}{c}\text { Disharmonious } \\
\quad(n=104)\end{array}$ & $\begin{array}{c}\text { Amicable } \\
(n=99)\end{array}$ & $\begin{array}{c}\text { Harmonious } \\
(n=181)\end{array}$ \\
\hline \multirow{2}{*}{\multicolumn{2}{|c|}{$\begin{array}{l}\text { Age } \\
\text { Gender ( } \% \text { of females })\end{array}$}} & $15.1(1.3)^{\mathrm{a}, \mathrm{b}}$ & $15.5(1.8)^{b}$ & $15.2(1.4)^{\mathrm{a}, \mathrm{b}}$ & $14.9(1.4)^{\mathrm{a}}$ \\
\hline & & 53.8 & 65.7 & 70.7 & 57.9 \\
\hline \multirow{4}{*}{$\begin{array}{l}\text { Solidarity } \\
\text { components }\end{array}$} & Family values consensus & $.06(.48)^{\mathrm{a}, \mathrm{b}}$ & $.21(.61)^{b}$ & $-.04(.43)^{\mathrm{a}}$ & $-.06(.75)^{\mathrm{a}}$ \\
\hline & Affectual & $2.36(.40)^{\mathrm{a}}$ & $2.36(.63)^{\mathrm{a}}$ & $3.55(.69)^{\mathrm{c}}$ & $3.26(.54)^{b}$ \\
\hline & Conflict & $2.03(.37)^{\mathrm{a}}$ & $3.22(.60)^{b}$ & $2.10(.77)^{\mathrm{a}}$ & $2.17(.58)^{\mathrm{a}}$ \\
\hline & A-to-P emotional support & $1.83(.40)^{\mathrm{a}}$ & $2.15(.63)^{b}$ & $3.63(.50)^{\mathrm{d}}$ & $2.38(.45)^{\mathrm{c}}$ \\
\hline \multirow{4}{*}{$\begin{array}{l}\text { Parenting } \\
\text { dimensions }\end{array}$} & M Acceptance & $3.26(.46)^{\mathrm{b}}$ & $2.94(.70)^{\mathrm{a}}$ & $3.68(.36)^{\mathrm{c}}$ & $3.61(.55)^{\mathrm{c}}$ \\
\hline & F Acceptance & $2.89(.64)^{b}$ & $2.48(.76)^{\mathrm{a}}$ & $3.49(.54)^{\mathrm{c}}$ & $3.41(.50)^{\mathrm{c}}$ \\
\hline & M Rejection & $1.38(.45)^{\mathrm{a}}$ & $1.70(.68)^{b}$ & $1.38(.56)^{\mathrm{a}}$ & $1.33(.45)^{\mathrm{a}}$ \\
\hline & F Rejection & $1.39(.54)^{\mathrm{a}}$ & $1.75(.73)^{b}$ & $1.40(.68)^{\mathrm{a}}$ & $1.24(.37)^{\mathrm{a}}$ \\
\hline \multirow{3}{*}{$\begin{array}{l}\text { Adolescents' } \\
\text { general } \\
\text { attachment }\end{array}$} & Anxiety & $2.43(.76)$ & $2.50(.88)$ & $2.40(.81)$ & $2.43(.78)$ \\
\hline & Close & $3.79(.85)$ & $3.74(1.05)$ & $3.72(1.05)$ & $3.76(.91)$ \\
\hline & Dependence & $3.53(.81)^{\mathrm{a}, \mathrm{b}}$ & $3.42(.87)^{\mathrm{a}}$ & $3.59(.80)^{\mathrm{a}, \mathrm{b}}$ & $3.72(.76)^{b}$ \\
\hline
\end{tabular}

Note. Sample of adolescents asked about parenting quality of fathers $(n=290)$ was smaller than the total sample of adolescents asked about motherchild parenting $(N=570)$. The family types distribution of adolescents asked about parenting of father was following: detached, $n=84$; disharmonious, $n=59$; amicable, $n=60$; harmonious, $n=87$. Means with different letters differ significantly from each other $(p<.01)$. A.-adolescents. P.-parents.

M-mothers. F-fathers. 
Table 4

Steps of Hierarchical Regressions Models for Mothers and Fathers Predicting Adolescent's Attachment Dimensions

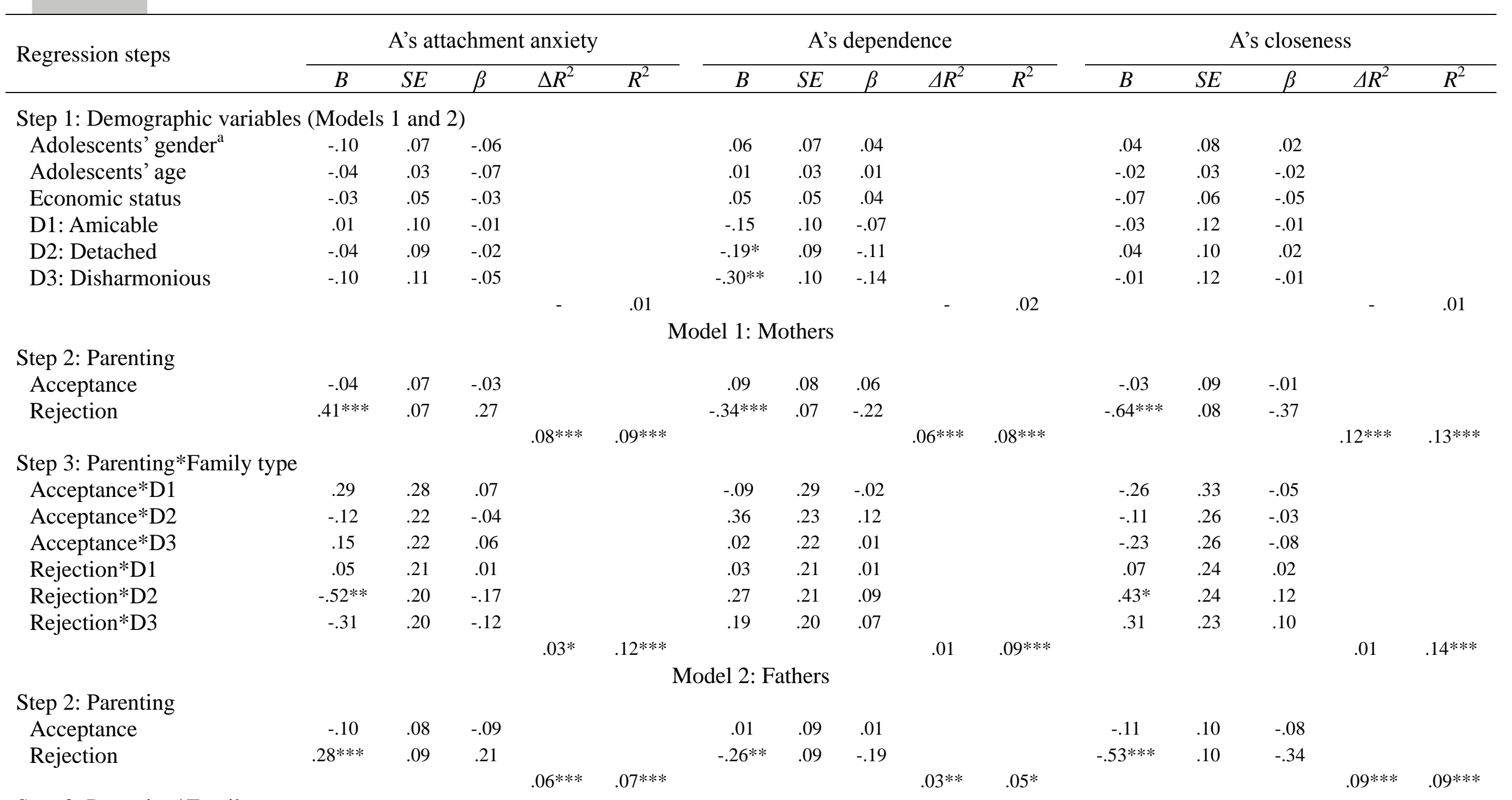

Step 3: Parenting*Family type 


\begin{tabular}{|c|c|c|c|c|c|c|c|c|c|c|c|c|c|c|c|}
\hline Acceptance*D1 & .27 & .29 & .10 & & & -.24 & .31 & -.09 & & & -.13 & .35 & -.04 & & \\
\hline Acceptance*D2 & -.08 & .25 & -.04 & & & .31 & .26 & .14 & & & .02 & .30 & .01 & & \\
\hline Acceptance*D3 & .17 & .27 & .09 & & & .10 & .28 & .05 & & & .10 & .31 & .05 & & \\
\hline Rejection*D1 & .29 & .32 & .11 & & & -.04 & .34 & -.01 & & & $-.82 *$ & .38 & -.26 & & \\
\hline Rejection*D2 & .01 & .32 & .01 & & & .01 & .34 & .01 & & & -.28 & .38 & -.09 & & \\
\hline \multirow[t]{2}{*}{ Rejection*D3 } & -.09 & .33 & -.04 & & & .25 & .34 & .11 & & & -.15 & .38 & -.06 & & \\
\hline & & & & .02 & $.09 * *$ & & & & .02 & $.08 *$ & & & & .03 & $.12 * * *$ \\
\hline
\end{tabular}

$* p<.05 . * * p<.01 . * * * p<.001 .{ }^{\mathrm{a}} 1$-males, 2 -females. Harmonious group was the reference group for D1-D3.

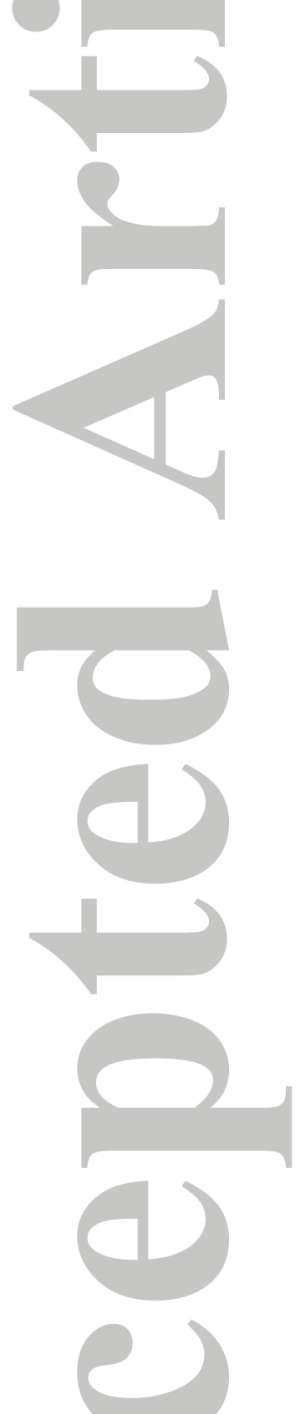



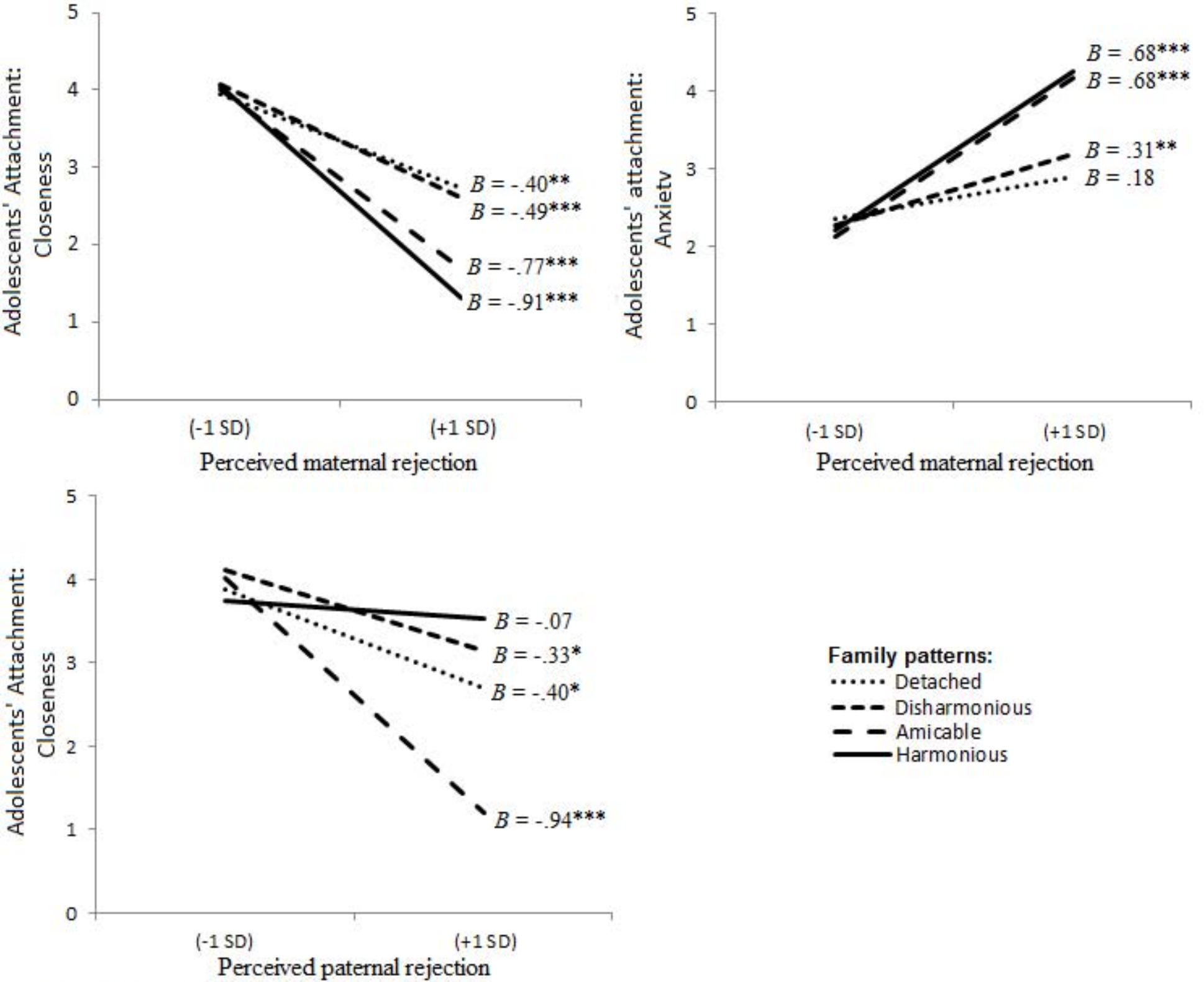

Family patterns:

...... Detached

- Disharmonious

- Amicable

- Harmonious 